OPEN ACCESS

Edited by:

Tzvi Dwolatzky,

Technion Israel Institute of

Technology, Israel

Reviewed by:

Fernando M. Runzer-Colmenares,

Scientific University of the South, Peru

Chuiguo Sun,

Peking University Third Hospital, China

*Correspondence:

Lin Tao

taolindr@163.com

tThese authors have contributed equally to this work

Specialty section:

This article was submitted to Geriatric Medicine,

a section of the journal

Frontiers in Medicine

Received: 09 December 2020 Accepted: 18 May 2021 Published: 20 July 2021

Citation:

Yang K, Pei L, Wen K, Zhou S and Tao L (2021) Investigating Research Hotspots and Publication Trends of

Spinal Stenosis: A Bibliometric Analysis During 2000-2018.

Front. Med. 8:556022.

doi: 10.3389/fmed.2021.556022

\section{Investigating Research Hotspots and Publication Trends of Spinal Stenosis: A Bibliometric Analysis During 2000-2018}

\author{
Keda Yang ${ }^{\dagger}$, Lei Pei ${ }^{\dagger}$, Kaicheng Wen, Siming Zhou and Lin Tao* \\ Department of Orthopaedics, First Hospital of China Medical University, Shenyang, China
}

Spinal stenosis is a common disease affecting the elderly that is present in a various forms. Its high incidence forces researchers to pay more attention and offer countermeasures. We used the Web of Science Core collection and PubMed database to obtain 5,606 scientific studies concerning spinal stenosis, and the number of publications maintained a roughly increasing trend from 108 in 2000 to 512 in 2018, only declining in 2011. Bibliometric analysis was conducted using the online analysis software CiteSpace and Bibliographic Item Co-Occurrence Matrix Builder (BICOMB). The United States maintains academic leadership in this field. The journal SPINE was the most authoritative, with 695 articles and an average of 12.73 citations. The exported major MeSH terms were further biclustered with gCLUTO according to co-word analysis to reveal research hotspots, including etiology, pathogenesis, clinical manifestation, conservative treatment, operative indication, internal implantation, and postoperative complications. After combination, the main topics focused on pathogenesis and surgical treatment. Narrowing causes flavum ligamentum hypertrophy, and posterior longitudinal ligament ossification is widely accepted. Additionally, minimally invasive surgery and internal implantation fixation are more valid in the clinic. Refining pathological classification and optimizing surgical methods and instrument properties will be important future research directions for spinal stenosis.

Keywords: research hotspots, publication trends, spinal stenosis, bibliometric analysis, MeSH terms

\section{INTRODUCTION}

Spinal stenosis involves pathological symptoms, such as narrowing of the spinal canal and shortening of the canal diameters, compression of the spinal cord, and the presence of neurological disturbance. According to the vertebral segments, narrowing occurs commonly in the cervical and lumbar spine and rarely has a thoracic appearance. An increasing risk of limb dysfunction and urinary and fecal incontinence exists in elderly individuals with spinal stenosis. By dissecting the anatomical structure of the spinal canal, bone hyperplasia and fibrous tissue adaptation are the main risks of spinal stenosis $(1,2)$. Additionally, the local inflammatory microenvironment, calcium maladjustment, and microbial infection contribute to disease development (3). Measurement of the canal diameter, observation of symptoms, and auxiliary examination with radiologic technology is the gold standard for a definite diagnosis 
and is widely adopted in the clinic. Once diagnosed, treatment varies according to the narrowing degree and clinical manifestation. Mild stenosis is usually asymptomatic and difficult to detect. No intervention is available that does not affect the normal life quality of life. Non-operation therapy is the first choice, including functional exercise, massage, and traction. The application of drugs, blockade, and acupuncture remains relatively controversial. However, if nervous compression manifestations, such as pain, numbness, and dysfunction of physical activity, have seriously affected severe stenosis patients (4), the treatment process is usually complicated, particularly in elderly individuals with vascular and neurological claudication. Clinical studies have shown that, among patients with lumbar spinal stenosis, with or without degenerative spondylolisthesis, decompression surgery plus fusion surgery did not result in better clinical outcomes at 2 and 5 years than decompression surgery alone (5). However, posterolateral instrumented fusion showed a greater improvement in the quality of life than decompression alone in another comparison (6). As discussed above, controversies exist regarding surgical choice and postoperative efficacy. Thus, the field of spinal stenosis warrants further exploration.

Bibliometrics, a cross-science of quantitative analysis of all knowledge carriers using mathematical and statistical methods, evaluates scientific achievements and treatises and predicts research trends in a particular field. It is a comprehensive knowledge system that integrates mathematics, statistics, and bibliography, mainly focusing on quantification. The number of documents, authors, and vocabularies are the measurement objects. Thus, an essential feature of bibliometrics is that the output must be "quantity." Quantitative research on the literature can be traced back to the beginning of the 20th century. In 1969, Alan Pritchard named this quantitative analysis method "bibliometrics." Recently, an increasing number of studies have assessed the contribution and trends of publications in various areas. Yao et al. regarded immunosuppression as a hotspot of sepsis by clustering keywords (7). Ahmad et al. identified the high-risk factors of Periodontology 2000 by synthesizing the study results of extensive dental institutions (8). These studies supported the reliability of bibliometrics in evaluating hotspots and directing trends of scientific research.

Presently, knowledge updates are constantly accelerating, and the experience of previous experts is slightly lagging, creating challenges for medical workers. Bibliometrics can effectively improve this situation. Before this study, no bibliometric articles were available on spinal stenosis. We adopted the biclustering method of bibliometrics to provide a comprehensive analysis of the current status of spinal stenosis. Our study aims to uncover hotspots and predict trends based on bibliometric analysis.

Abbreviations: BICOMB, Bibliographic Item Co-Occurrence Matrix Builder; $\mathrm{MeSH}$, Medical Subject Headings; WoS, Web of Science Core Collection; NCBI, National Center for Biotechnology Information; JCR, Journal Citation Reports; MRI, Magnetic Resonance Imaging; ASIF, anterior subcutaneous internal fixator; IPD, interspinous process decompression; NSAIDs, Nonsteroidal antiinflammatory drugs.

\section{METHODS}

\section{Data Source and Collection}

All literature was retrieved from the Web of Science Core Collection (WoS) from January 2000 to December 2018. The retrieving process was completed in Dec 30, 2019 to reduce the deviation within a constantly updated database. The key indexes of our study were "spinal stenosis" and "English" for language. Five thousand six hundred and six pieces of literature were collected and the document types included ARTICLE and REVIEW, improving the comprehensive feature of our research. Medical subjects Headings ( $\mathrm{MeSH}$ ) terms express the main idea of a piece of literature, identified for the following co-word associated analysis (9). For document download, we used the PubMed database, a biomedical information retrieval system developed by National Center for Biotechnology Information (NCBI) that was relatively complete in medicine. It was convenient to use the MeSH terms directly on PubMed as the keywords with a higher relevance. Our data obtained from the Web of Science Core Collection was converted into txt format first and conducted for quantitative and statistical analysis by CiteSpace, a "citation space" for visualization and the Online Analysis Platform of Literature Metrology (http://bibliometric. $\mathrm{com} /$ ) for bibliometrics. The downloaded documents were also converted into txt format and inducted the research generality and evolutionary trend according to co-word and biclustering analysis of $\mathrm{MeSH}$ terms by Bibliographic Item Co-Occurrence Matrix Builder (BICOMB) and gCLUTO. It was necessary to note that three investigators carried out literature screening independently based on the abstracts, conclusions, or full articles in our preliminary experiment. The consistency was up to 0.95 . And we discussed the differences and reached the consensus, which reflected the reliability of our data retrieval.

\section{Data Analysis}

We divided the analysis process into three parts: content association, high-frequency $\mathrm{MeSH}$ terms filtering, and scientific direction prediction.

Citespace is an excellent bibliometric software that can reveal the potential connection between documents visually with the form of scientific knowledge maps (10). It is developed based on the WoS data format. Cooperative network analysis, cooccurrence analysis, and co-citation analysis can be performed according to the downloaded data. But data from non-WoS databases need to be converted to the WoS data format first. And data dimensions of the corresponding database applies to its corresponding scope. We concatenated the retrieved publications with the similarity in journals, publication years, countries, authors, and languages by using Citespace, which helped us select nodes for different focuses conveniently and precisely.

BICOMB were developed by Cui et al. from Department of Information Management and Information System (Medical) in China Medical University (11). Major MeSH terms could be exported to represent the publication core and rank the occurring frequency with Microsoft Excel and GoPubMed. The screening publications were analyzed and checked with a designed model in XML format to extract the main information in the beginning. 


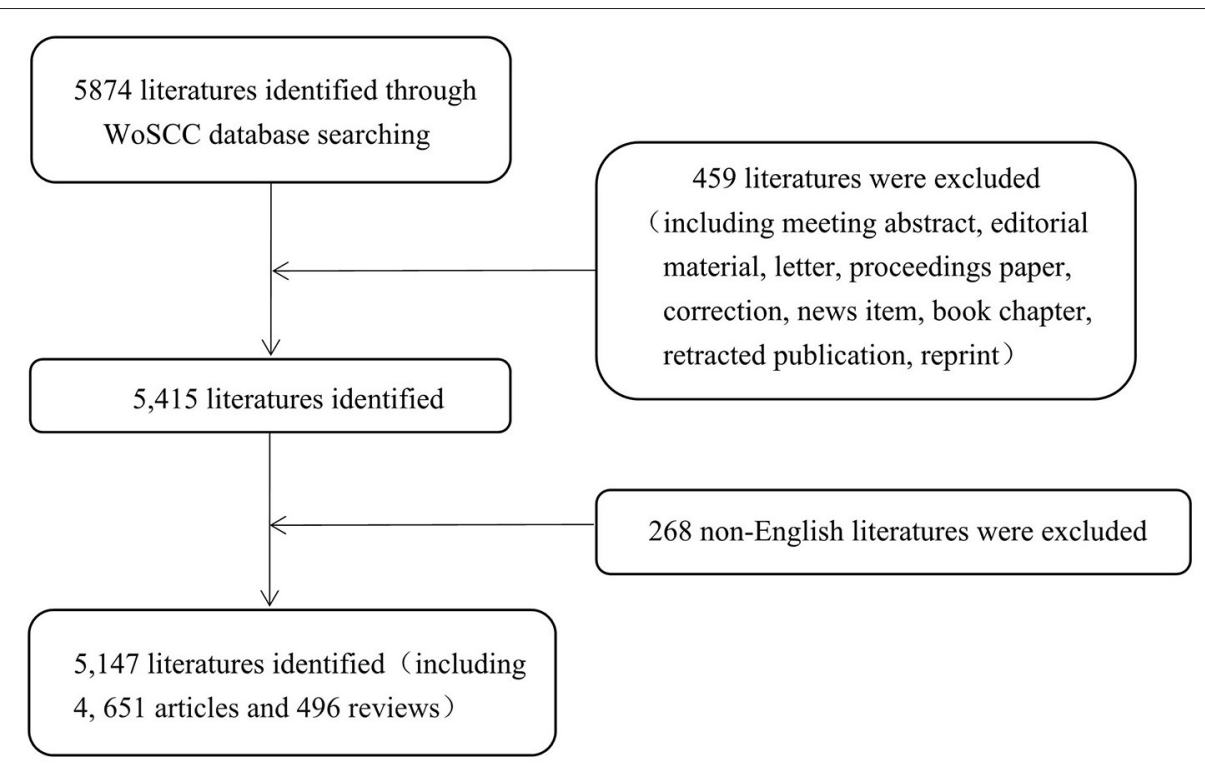

FIGURE 1 | Flow chart of literature filtering involved in this study.

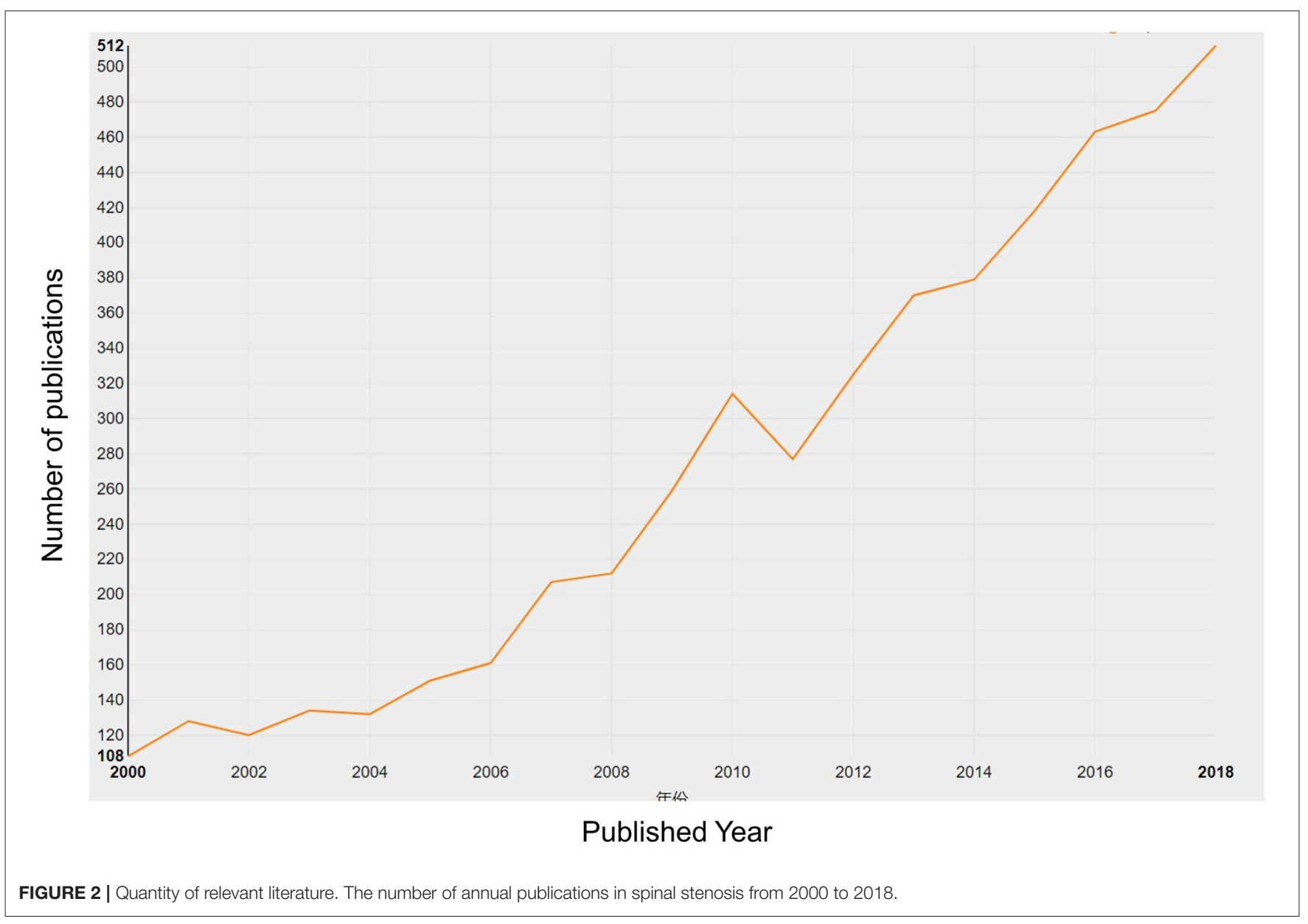




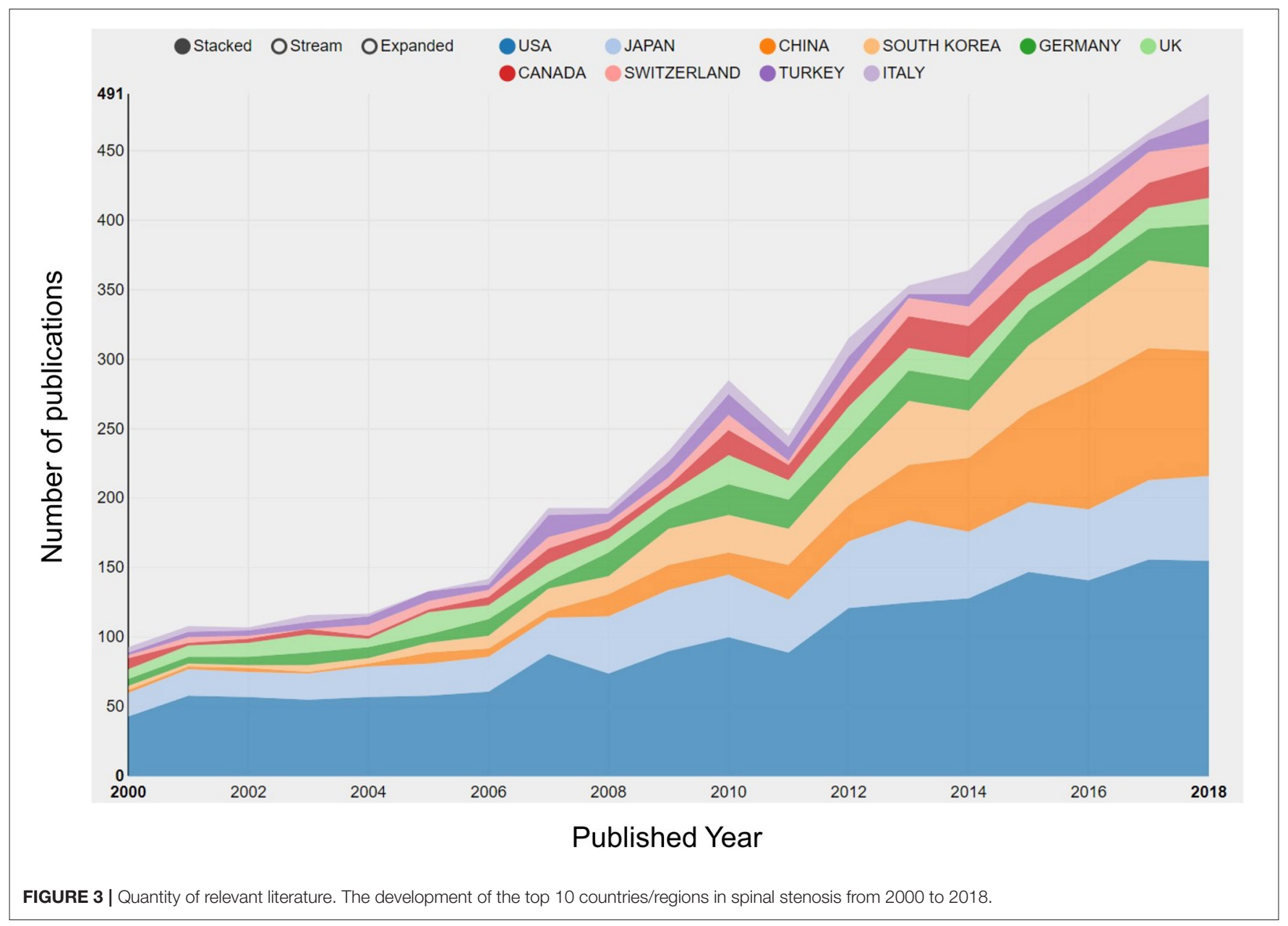

The filter of high-frequency $\mathrm{MeSH}$ terms was performed in a binary matrix after preliminary interception through a particular threshold. And the latent biomedical principle could be excavated with association and clustering analysis in terms of the results from a binary matrix. Then both the major MeSH terms and their networks were conducted for visualization in graph.

gCLUTO were utilized to carry out biclustering analysis of the major $\mathrm{MeSH}$ terms from BICOMB. There are four cluster mothed in gCLUTO-Repeated Bisection, Direct, Agglomerative, and Graph-among which we selected Repeated Bisection with the highest preciseness. And the classified results of these terms would be extracted in two forms: matrix visualization and mountain visualization (12). In matrix visualization, colors represented values in the raw data matrix. White equaled the central value "zero," positive values increased with red deepening, and negative values were depicted with green. Rows of matrix held columns with the same class. Mountain visualization could make accurate predictions with multidimensional scaling. Peak number reflected the clustering number in matrix. Mountain shape provided a rough estimate of data distribution in each cluster. The peak altitude is proportional to the similarity and volume is proportional to the number of containing objects in a cluster. Additionally, the peak
TABLE 1 | The top 10 countries/regions: article counts and centrality of publications in spinal stenosis research.

\begin{tabular}{llcc}
\hline Rank & Country/region & Article counts & Centrality index \\
\hline 1 & USA & 1,803 & 0.71 \\
2 & Japan & 711 & 0.03 \\
3 & China & 566 & 0.01 \\
4 & South Korea & 479 & 0.01 \\
5 & Germany & 293 & 0.23 \\
6 & UK & 248 & 0.14 \\
7 & Canada & 218 & 0.08 \\
8 & Switzerland & 173 & 0.04 \\
9 & Turkey & 169 & 0.01 \\
10 & Italy & 131 & 0.01 \\
\hline
\end{tabular}

color is related to the standard deviation within the cluster: red for low value and blue for high value. And we measured the clustering number constantly to reach the optimal visualized graph to investigate the research hotspots and publication trends of spinal stenosis. 


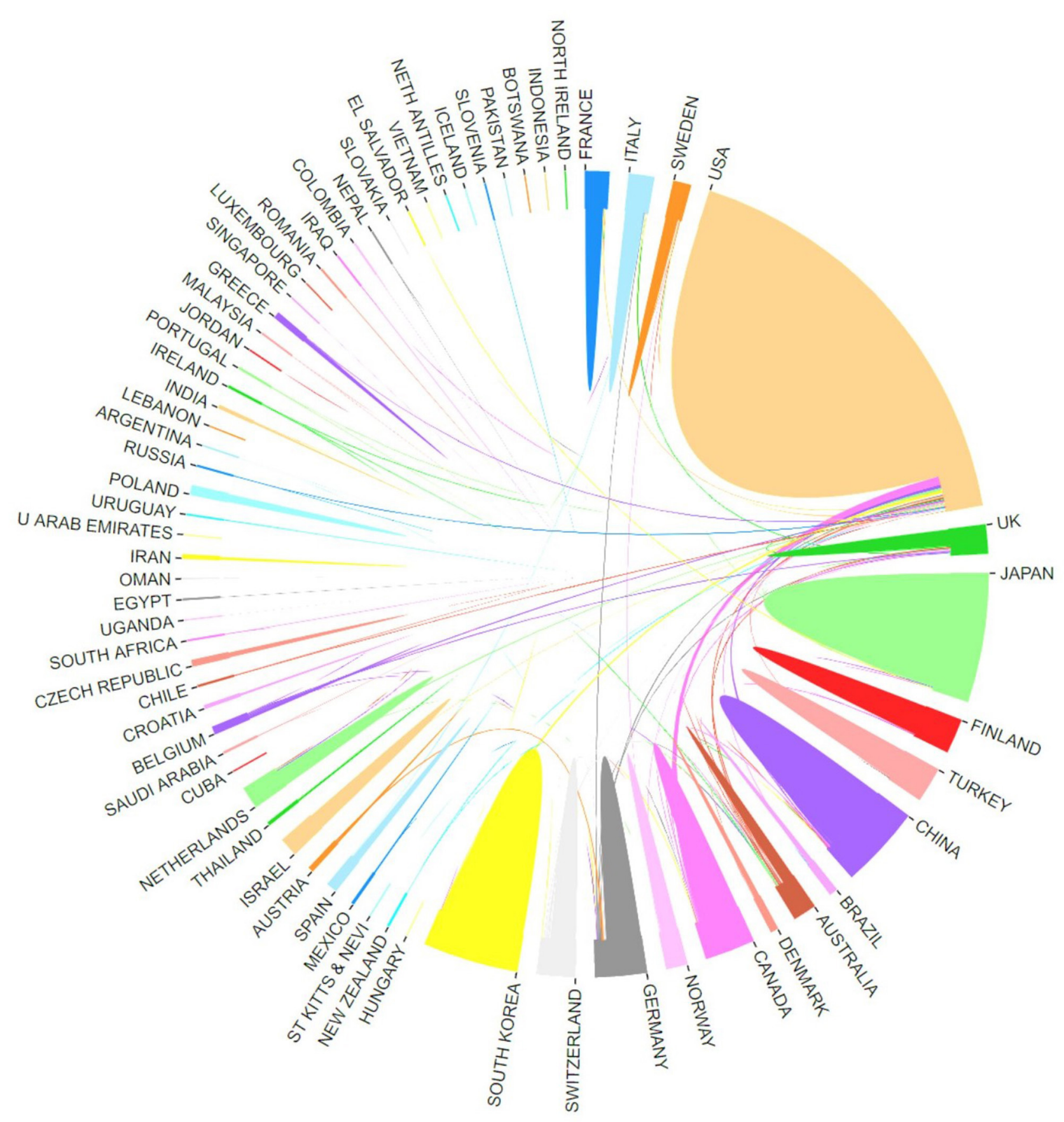

FIGURE 4 | Most active countries or regions. The cooperation of countries/regions involved in spinal stenosis research.

\section{RESULTS}

\section{Quantity of Relevant Literature}

Regarding literature screening, we set up the keywords as "spinal stenosis" and "language = English." Our retrieval period ranged from January 1, 2000, to December 31, 2018. In total, 5,147 publications were involved in 4,651 articles and 496 reviews (Figure 1). The number of publications generally increased from
108 in 2000 to 512 in 2018, and only declined in 2011 (Figure 2). Additionally, the growth rate was also improving.

\section{Distribution Characteristics of Literature Most Active Countries or Regions}

The county or regional distribution of publications in bibliometric analysis has focused on the hotspots of research 
TABLE 2 | The top 10 institutions for most publications in spinal stenosis research.

\begin{tabular}{|c|c|c|c|c|c|c|c|c|c|}
\hline Rank & Institution & $\begin{array}{l}\text { Article } \\
\text { counts }\end{array}$ & $\begin{array}{c}\text { Total } \\
\text { number of } \\
\text { citations }\end{array}$ & $\begin{array}{l}\text { Average } \\
\text { number of } \\
\text { citations }\end{array}$ & $\begin{array}{c}\text { Total number } \\
\text { of first } \\
\text { authors }\end{array}$ & $\begin{array}{c}\text { Total number } \\
\text { of first } \\
\text { author citations }\end{array}$ & $\begin{array}{l}\text { Average number } \\
\text { of first } \\
\text { author citations }\end{array}$ & $\begin{array}{l}\text { Centrality } \\
\text { index }\end{array}$ & Country \\
\hline 1 & Seoul Natl Univ & 231 & 725 & 3.14 & 64 & 259 & 4.05 & 0.04 & Korea \\
\hline 2 & Univ Washington & 169 & 3,408 & 20.17 & 33 & 369 & 11.18 & 0.1 & US \\
\hline 3 & Univ Toronto & 155 & 994 & 6.41 & 31 & 157 & 5.06 & 0.12 & Canada \\
\hline 4 & Harvard Univ & 127 & 3,001 & 23.63 & 34 & 606 & 17.82 & 0.15 & US \\
\hline 5 & Yonsei Univ & 97 & 363 & 3.74 & 41 & 157 & 3.83 & 0.03 & Korea \\
\hline 6 & Kuopio Univ Hosp & 95 & 1,543 & 16.24 & 23 & 194 & 8.43 & & Finland \\
\hline 7 & Cleveland Clin & 88 & 386 & 4.39 & 25 & 99 & 3.96 & 0.02 & US \\
\hline 8 & $\begin{array}{l}\text { Univ Calif San } \\
\text { Francisco }\end{array}$ & 87 & 1,344 & 15.45 & 35 & 128 & 3.66 & 0.1 & US \\
\hline 9 & Vanderbilt Univ & 86 & 1,815 & 21.1 & 32 & 161 & 5.03 & 0.03 & US \\
\hline 10 & Johns Hopkins Univ & 84 & 194 & 2.31 & 34 & 62 & 1.82 & 0.02 & US \\
\hline
\end{tabular}

in spinal stenosis by refining data sources. In our study, we demonstrated the top ten countries leading in the field of spinal stenosis according to the publication counts (Figure 3). The United States was far ahead of other counties with 1,803 studies, followed by Japan (711), China (566), and South Korea (479). Notably, the research level in Northeast Asian countries had gradually increased and surpassed that in Europe over time. We attributed this phenomenon to economic development. Additionally, the centrality index also reflected the core influence to evaluate research value more exactly. The United States maintained a leading position with 0.71 centrality. All of the other countries had a lower influence, among which Germany had the highest centrality at 0.23 (Table 1 ). The cooperative network was formed between many countries and the level was relatively higher in leading countries (Figure 4).

\section{Top Ten Active Institutions}

We also demonstrated the top ten institutions for spinal stenosis research ordered by the publication number. They were Seoul Natl Univ, Univ Washington, Univ Toronto, Harvard Univ, Yonsei Univ, Kuopio Univ Hosp, Cleveland Clin, Univ Calif San Francisco, Vanderbilt Univ, and Johns Hopkins Univ (Table 2). Among them, more than half were from the United States, two institutions were from Korea, and only one belonged to Finland and Canada, respectively, in line with the distribution characteristics of countries. Seoul Natl Univ (231), Univ Washington (169), Univ Toronto (155), and Harvard Univ (127) published more than one hundred articles and their average citations were $3.14,20.17,6.14$, and 23.63 , respectively. It was clear to see that the institutions in the United States had relatively higher average citation and centrality, which determined the credibility (Table 2). With extensive academic communication among scholars, it was necessary to develop closer research collaboration between various institutions for the lower level (0.015 on density map) (Figure 5).

\section{Distribution Characteristics of Authors and Journals}

There were a total of 15,718 authors involved in the field of spinal stenosis through our retrieval. We paid more attention

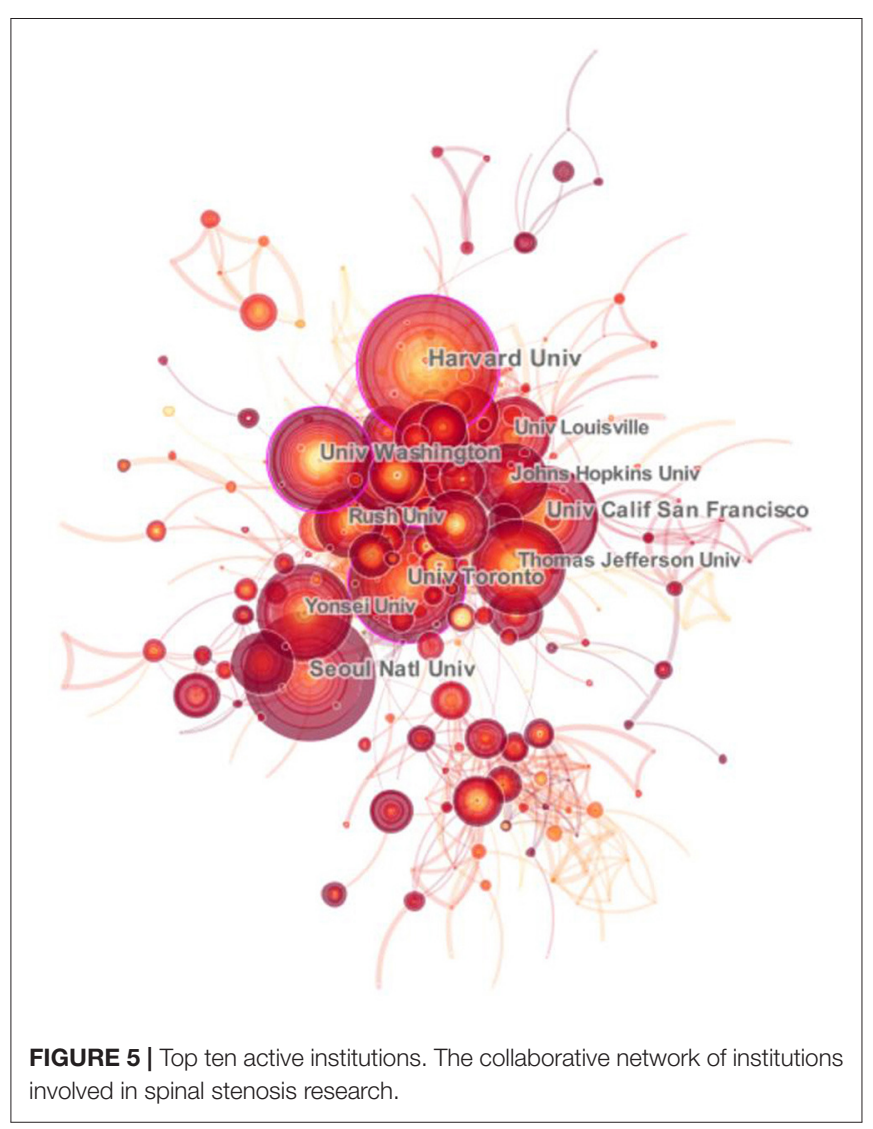

to the ten most active authors including Lee $\mathrm{SH}$, Kim $\mathrm{HJ}$, Manchikanti L, Lee JH, and Konno S in order of published counts (Table 3). The top three among them were Lee SH, Kim HJ, and Manchikanti L with the number of 73, 60, and 54. They came from Pusan National University Yangsan Hospital in Korea, Seoul National University Bundang Hospital in Korea, and Pain Management Center of Paducah in America, respectively. It was noted that they contributed most to the development of 
TABLE 3 | The top 10 most productive authors and co-cited authors contributing to publications in spinal stenosis research.

\begin{tabular}{|c|c|c|c|c|c|c|c|c|}
\hline Rank & Author & $\begin{array}{l}\text { Article } \\
\text { counts }\end{array}$ & $\begin{array}{l}\text { Total number } \\
\text { of citations }\end{array}$ & $\begin{array}{c}\text { First author } \\
\text { citation counts }\end{array}$ & $\begin{array}{l}\text { Corresponding } \\
\text { author }\end{array}$ & $\begin{array}{l}\text { Co-cited } \\
\text { author }\end{array}$ & $\begin{array}{l}\text { Citation } \\
\text { counts }\end{array}$ & $\begin{array}{c}\text { Centrality } \\
\text { index }\end{array}$ \\
\hline 1 & Lee, SH & 73 & 360 & 37 & 10 & Deyo RA & 812 & 0.18 \\
\hline 2 & Kim, HJ & 60 & 269 & 126 & 3 & Katz JN & 659 & 0.1 \\
\hline 3 & Manchikanti, L & 54 & 1,610 & 1,520 & 50 & Weinstein JN & 630 & 0.1 \\
\hline 4 & Lee, JH & 46 & 163 & 103 & 16 & Atlas SJ & 448 & 0.09 \\
\hline 5 & Konno, S & 45 & 294 & 93 & 3 & Boden SD & 397 & 0.08 \\
\hline 6 & Kikuchi, S & 39 & 317 & 0 & 0 & Amundsen $\mathrm{T}$ & 383 & 0.1 \\
\hline 7 & Lurie, JD & 37 & 1,290 & 113 & 9 & Herkowitz HN & 347 & 0.16 \\
\hline 8 & Weinstein, JN & 36 & 1,431 & 778 & 7 & Verbiest H & 309 & 0.08 \\
\hline 9 & Watanabe, K & 36 & 176 & 61 & 7 & Turner JA & 289 & 0.07 \\
\hline 10 & Vaccaro, AR & 34 & 234 & 50 & 11 & Epstein NE & 288 & 0.08 \\
\hline
\end{tabular}

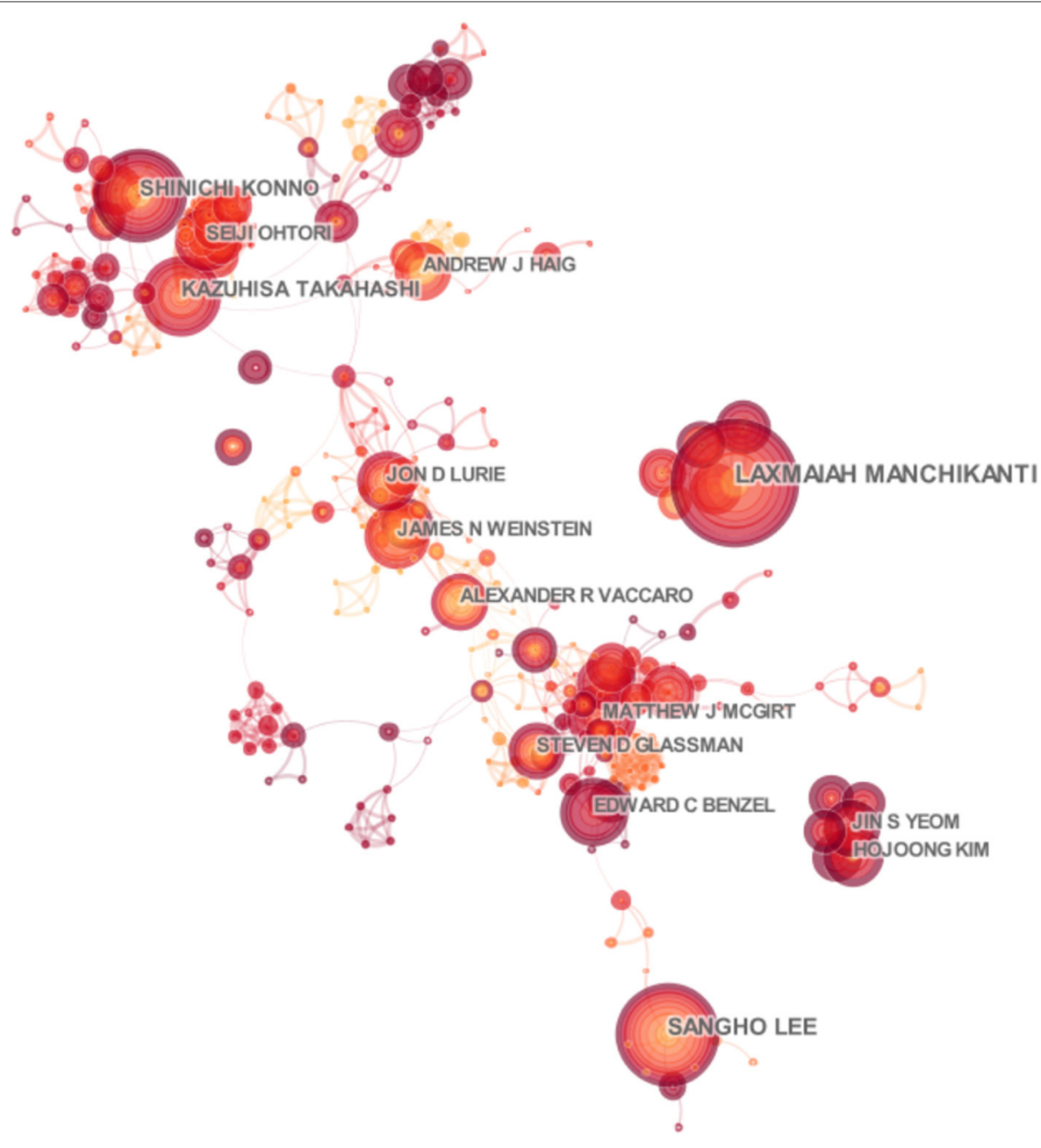

FIGURE 6 | Distribution characteristics of authors. The associated network of productive authors.

the scientific study, though there was not a large gap with other authors, which also showed the research momentum of spinal stenosis. We drew an associated network based on the integration of cited and co-cited authors by CiteSpace at the same time (Figures 6, 7). Deyo RA was the co-cited author with the most co-citation (812). Katz JN (659) and Weinstein JN (630), close to each other, ranked second and third. Additionally, the centrality index of them was $0.18,0.10$, and 


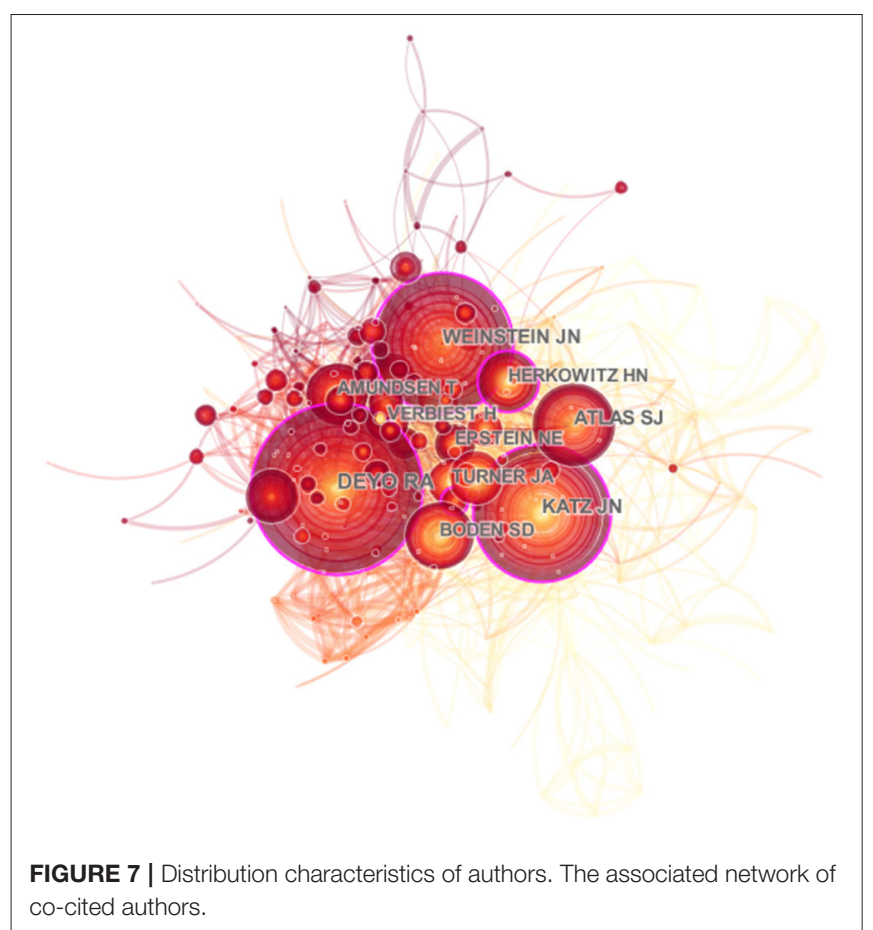

0.10 which reflected the credibility and authority of their research (Table 3).

In total, there were 735 journals involved in this field. SPINE and EUROPEAN SPINE JOURNAL are the top two journals in order of article counts and total number of citations which were $695,8,847$, and $426,2,908$, respectively. Both of them were Q2 in JCR 2018 standards. The other journals in the top ten journals were shown in Table 4. The average number of citations and the impact factor were also important indicators for evaluating the influence of journals. PAIN PHYSICIAN (15.91) was the highest in terms of the average number of citations, followed by SPINE (12.73) and JOURNAL OF NEUROSURGERY-SPINE (7.09). According to the impact factor, JOURNAL OF SPINE JOURNAL (3.196) was the highest, JOURNAL OF NEUROSURGERYSPINE (2.998) ranked second, and PAIN PHYSICIAN (2.942) ranked third. The number of articles published in these ten journals accounted for $42.47 \%$. It was obvious that these ten journals laid a solid foundation for subsequent research on spinal stenosis.

\section{Research Hotspots of Spinal Stenosis Based on MeSH Clusters}

Through statistical and quantitative analyses of the publications from January 1, 2000, to December 31, 2018, 3,810 major $\mathrm{MeSH}$ and $\mathrm{MeSH}$ subheading terms were identified, with a total frequency of 23,785 times. After repeatedly proofreading and balancing, the major $\mathrm{MeSH}$ and $\mathrm{MeSH}$ subheading terms with occurrence frequencies of 56 times and above were regarded as high-frequency terms. Altogether, fifty-seven terms were high in appearance with a total frequency of 11,754 , accounting for $49.42 \%(11,754 / 23,785)$ (Table 5). The major $\mathrm{MeSH}$ terms/subheading MeSH terms, spinal stenosis/surgery and lumbar vertebrae/surgery, appeared more than one thousand or even close to two thousand times, reflecting the predilection segment of lumbar vertebrae and the treatment method of surgery. Biclustering helped classify these high-frequency major $\mathrm{MeSH}$ and $\mathrm{MeSH}$ subheading terms, convenient to refine the main topics of spinal stenosis. Thereafter, the results were visualized in the form of a matrix and mountain graph. The color was the core property to reflect the raw matrix value in matrix visualization. The balanced point was white; red represented a positive value, and green represented a negative value, both of which expressed a positive correlation. In the matrix graph, clusters are separated by black horizontal lines, and each row is an individual category. Thus, seven clusters were observed in our matrix (Figure 8). The row and column tags represented the high-frequency major $\mathrm{MeSH}$ terms/MeSH subheading terms and the PMIDs of articles, respectively. When the matrix was exhibited in the dendrogram, the top and left layers revealed the association with different indexes. In Figure 8, the top tree indicates the relationships among articles, and the left tree indicates the relationships among high-frequency major $\mathrm{MeSH}$ terms/MeSH subheading terms. gCLUTO could also rearrange the attitude of rows in the initial matrix to integrate similar rows (Table 6). In our mountain visualization, seven peaks existed from 0 to 6 , revealing seven clusters after biclustering (Figure 9). In the 3D landform, the properties of each cluster were visualized by comparing the location, volume, altitude, and color of the corresponding peaks. The location of peaks represents the relative similarity among different clusters, with a higher location for closer clusters. Both the volume and altitude referred to the internal features in clusters. A greater volume reflected more objects containing major $\mathrm{MeSH}$ and $\mathrm{MeSH}$ subheading terms, and the altitude demonstrated the internal similarity in direct proportion. Furthermore, the color of the peak reflected the deviation degree of the dataset, equal to the standard deviation. Cluster 5 with a relative red peak referred to a lower value and a higher value with the trend of bluing in our study (Figure 9). Similar to our analysis above, the major $\mathrm{MeSH}$ and $\mathrm{MeSH}$ subheading terms were refined into the following seven clusters:

Effect of medical imaging on the diagnosis of spinal stenosis (Cluster 0),

Etiology of spinal stenosis with different pathological symptoms (Cluster 1),

Pathogenesis of spinal stenosis (Cluster 2),

Options of surgical method under particular conditions and adverse effects (Cluster 3 ),

Role of instrumentations in rehabilitation of patients (Cluster 4),

Surgical indications of spinal stenosis (Cluster 5),

Non-operative therapeutic means of spinal stenosis (Cluster 6).

\section{DISCUSSION}

We have examined previous literature concerning spinal stenosis using retrieval, characterization, and clustering. The number of articles published has generally maintained an upward trend with 
TABLE 4 | The top 10 journals contributing to publish articles in spinal stenosis research.

\begin{tabular}{|c|c|c|c|c|c|c|c|c|}
\hline Rank & Institution & $\begin{array}{l}\text { Article } \\
\text { counts }\end{array}$ & $\begin{array}{c}\text { Percentage } \\
(N / 5,147)\end{array}$ & $\begin{array}{c}\text { Total number } \\
\text { of citations }\end{array}$ & $\begin{array}{l}\text { Average number } \\
\text { of citations }\end{array}$ & $\begin{array}{c}\text { IF } \\
(2018)\end{array}$ & $\begin{array}{c}\text { Quartile in } \\
\text { category (2018) }\end{array}$ & $\mathrm{H}$-index \\
\hline 1 & Spine & 695 & $13.50 \%$ & 8,847 & 12.73 & 2.903 & Q2 & 228 \\
\hline 2 & European Spine Journal & 426 & $8.28 \%$ & 2,908 & 6.83 & 2.513 & Q2 & 117 \\
\hline 3 & Spine Journal & 221 & $4.29 \%$ & 1,148 & 5.19 & 3.196 & Q0 & 94 \\
\hline 4 & Journal of Neurosurgery-Spine & 215 & $4.18 \%$ & 1,525 & 7.09 & 2.998 & Q3 & 84 \\
\hline 5 & World Neurosurgery & 148 & $2.88 \%$ & 131 & 0.89 & 1.723 & QO & 85 \\
\hline 6 & Journal of Spinal Disorders \& Techniques & 133 & $2.58 \%$ & 936 & 7.04 & 0 & Q4 & 85 \\
\hline 7 & Pain Physician & 123 & $2.39 \%$ & 1,957 & 15.91 & 2.942 & Q0 & 87 \\
\hline 8 & Neurosurgery & 88 & $1.71 \%$ & 557 & 6.33 & 4.13 & Q3 & 183 \\
\hline 9 & BMC Musculoskeletal Disorders & 69 & $1.34 \%$ & 350 & 5.07 & 2.002 & Q3 & 81 \\
\hline 10 & Journal of Korean Neurosurgical Society & 68 & $1.32 \%$ & 123 & 1.81 & 1.187 & QO & 29 \\
\hline
\end{tabular}

a narrow fluctuation. In 2011, an obvious decline occurred but the number rose again in the subsequent year. MeSH terms can reflect the main idea of the literature and the combination with a mass of accurate $\mathrm{MeSH}$ terms can reveal the hotspots and trends in research fields. Next, based on the statistical analysis of BICOMB software, "spinal stenosis" has always maintained the highest occurring frequency, despite declining in individual years with the main trend of articles. Finally, the software gCLUTO divided these articles into some clusters according to the similarity and co-word analysis of MeSH terms. Using the above process, we can identify the knowledge hierarchy and research anticipation of spinal stenosis.

Cluster 0 focuses on the effect of medical imaging on the diagnosis. In the final analysis, spinal stenosis is a pathological change caused by morphological changes of the spine column. Fluoroscopy examination is indispensable to determine the site, severity, and nature of the lesion. To characterize stenosis more precisely, studies have made detailed classifications according to different criteria in morphology. Stenosis development is closely associated with the anatomic variation, including that associated with vertebrae, soft tissue structure, spinal canal, and segmental sagittal diameter. Among them, the common choice to classify is the change in the spinal diameter at different segments and sections (13). The evolutionary tendency of stenosis, whether causing neuropathy and requiring surgical intervention or not, will be speculated according to the numerical standards based on morphologic change. Additionally, the narrowing degree in one segment may suggest corresponding changes and developing trends in other segments (14). Presently, clinicians manually segment the spinal canal area using CT images and measure the anteroposterior diameter of the spinal canal to diagnose whether the patient has spinal stenosis, leading to a workload and stronger subjectivity. The development of artificial intelligence contributes to precise mastery of morphologic imaging changes in disease progression by using deep learning technology in computer diagnosis.

Cluster 1 focuses on the etiology of spinal stenosis using different pathological symptoms. Spinal stenosis is only a generalization of the narrowing of the spinal canal in morphology. Various symptoms may be secondary to the physiological structure change and great differences exist in the causes of these concomitant symptoms. Several neurological symptoms, such as limb numbness, low back pain, and claudication, occur in the patients, most often due to the complication of nerve compression. Cervical stenosis usually results in limb paresthesia, dexterity dysfunction, imbalance, and neck pain (15). However, cervical spondylosis relates to lesion sites, tissue involvement degree, and individual differences and is classified into radiculopathy, myelopathy, and vertebral artery types instead of a simple disc-protrusion or slipped disc (16). Lumbar stenosis always leads to numbness in the lower limbs, low back pain, and even cauda equina compressive symptoms. According to the urgency of incidence, different pathogenic possibilities exist, such as laminar thickening, facet hyperplasia, and vertebral dislocation. Accurate analysis of the etiology is an inevitable requirement for further disposition in all circumstances.

Cluster 2 focuses on the pathogenesis of spinal stenosis including pathology structures, segments, and sections. Additionally, these mainly involve the ligamentum flavum and intervertebral disc, cervical and lumbar spine, and sagittal and transverse diameters. Morphological changes in the soft tissue around the spinal canal are the main characteristics of spinal stenosis. Ligamentum flavum forms the dorsal wall of the spinal canal, obviously causing narrowness when thickening. Regarding the reason for thickening, studies have identified the epiligament in the ligamentum flavum, comprising collagenous fibers, while enlargement of the epiligament led to more collagenous than natural elastic fibers and canal tapering. Furthermore, the ligamentum flavum area has been compared with more sensitive measurement parameters than the ligament flavum thickness, playing a more valuable role (17). Close to the ventral wall of the canal, the herniation of intervertebral disc would narrow the spinal canal. Similarly, at the ventral wall, ossification of the posterior longitudinal ligament is also a risk factor. Genetic mutations causing ectopic osteogenesis of the ligament may account for the ossification phenomenon (18). Until now, Pavlov's ratio, the ratio of the sagittal diameter of spinal canal to that of the corresponding vertebral body, is a reliable diagnostic basis of stenosis. However, tissues that are not bone structure 
TABLE 5 | High-frequency major MeSH terms from the involved publications on spinal stenosis ( $n=23,785)$.

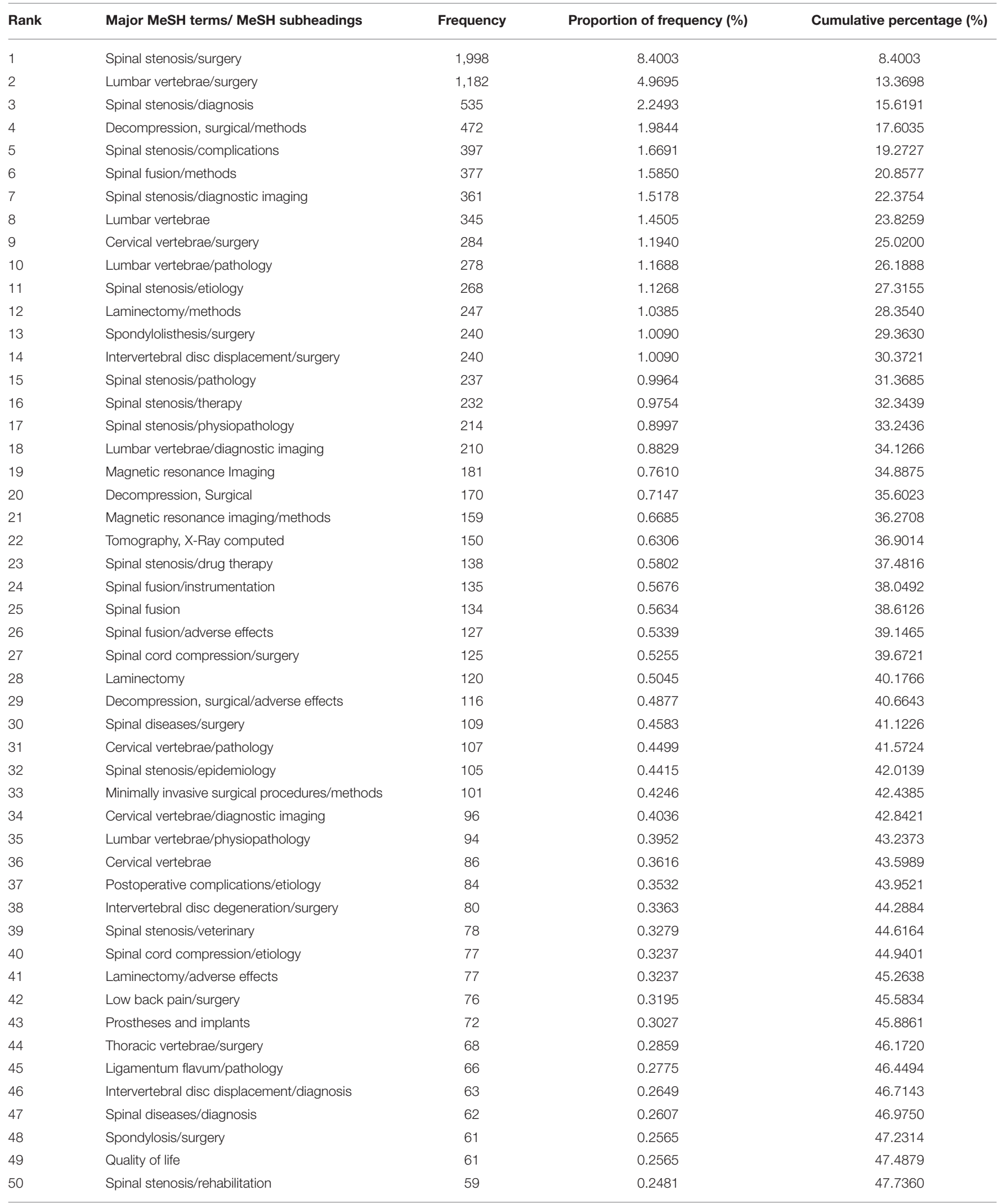


TABLE 5 | Continued

\begin{tabular}{llccc}
\hline Rank & Major MeSH terms/ MeSH subheadings & Frequency & Proportion of frequency (\%) & Cumulative percentage (\%) \\
\hline 51 & Spinal canal/surgery & 59 & 0.2481 & 47.9840 \\
52 & Internal fixators & 58 & 0.2439 & 48.2279 \\
53 & Decompression, surgical/instrumentation & 58 & 0.2439 & 48.4717 \\
54 & Spinal osteophytosis/surgery & 57 & 0.2396 & 48.7114 \\
55 & Spinal canal/pathology & 56 & 0.2354 & 48.9468 \\
56 & Lumbar vertebrae/injuries & 56 & 0.2354 & 49.1823 \\
57 & Low back pain/etiology & 56 & 0.2354 & 49.4177
\end{tabular}

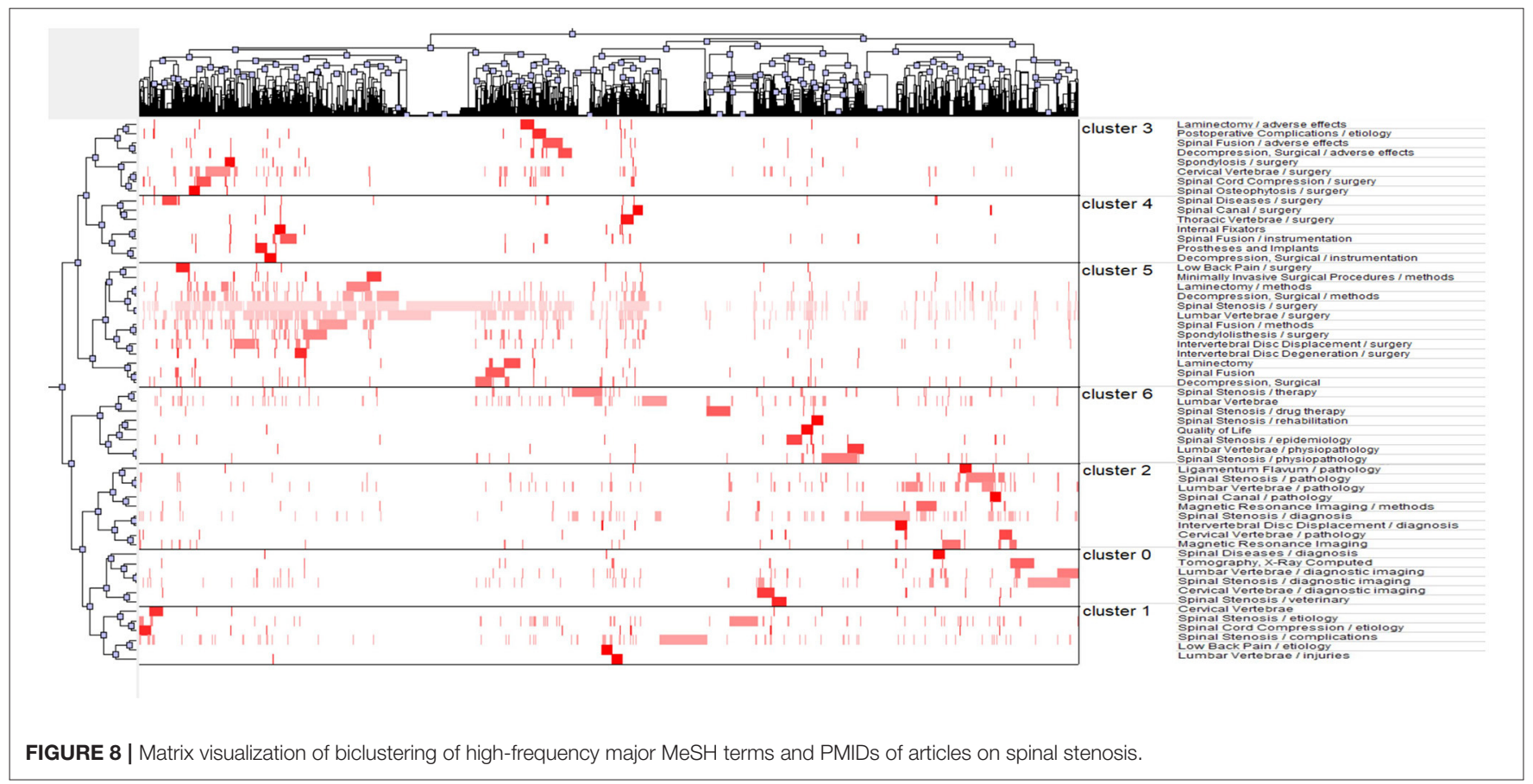

TABLE 6 | High-frequency major MeSH a terms-source articles matrix (localized).

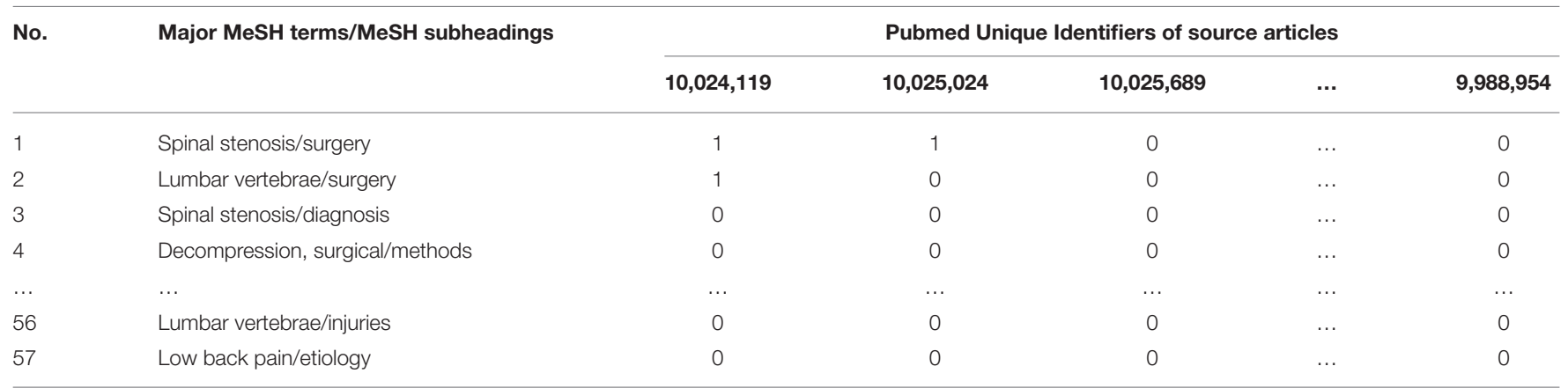

shown on X ray are less studied. Magnetic Resonance Imaging (MRI), which reveals the pathological changes in soft tissues, is an appropriately effective auxiliary to clarify the pathogenesis. In recent studies, a comprehensive comparison was made between the Pavlov's ratio and MRI scan, revealing a moderate correlation (19). More specific and extensive evaluation of MRI images and traditional diagnostic criteria is conducive to dissect the complex pathogenesis and symptomatic treatment. Additionally, we believe molecular biology will promote the determination of pathogenesis through genomics, transcriptomics, and proteomics analysis of the ligaments and disc tissues. Targeted specific drug design is the research trend for stenosis treatment.

Cluster 3 focuses on the surgical method options under particular conditions and inspection of adverse effects in failure cases. According to the follow-up and postoperative recovery analysis of many past cases, it is not the optimal procedure for 


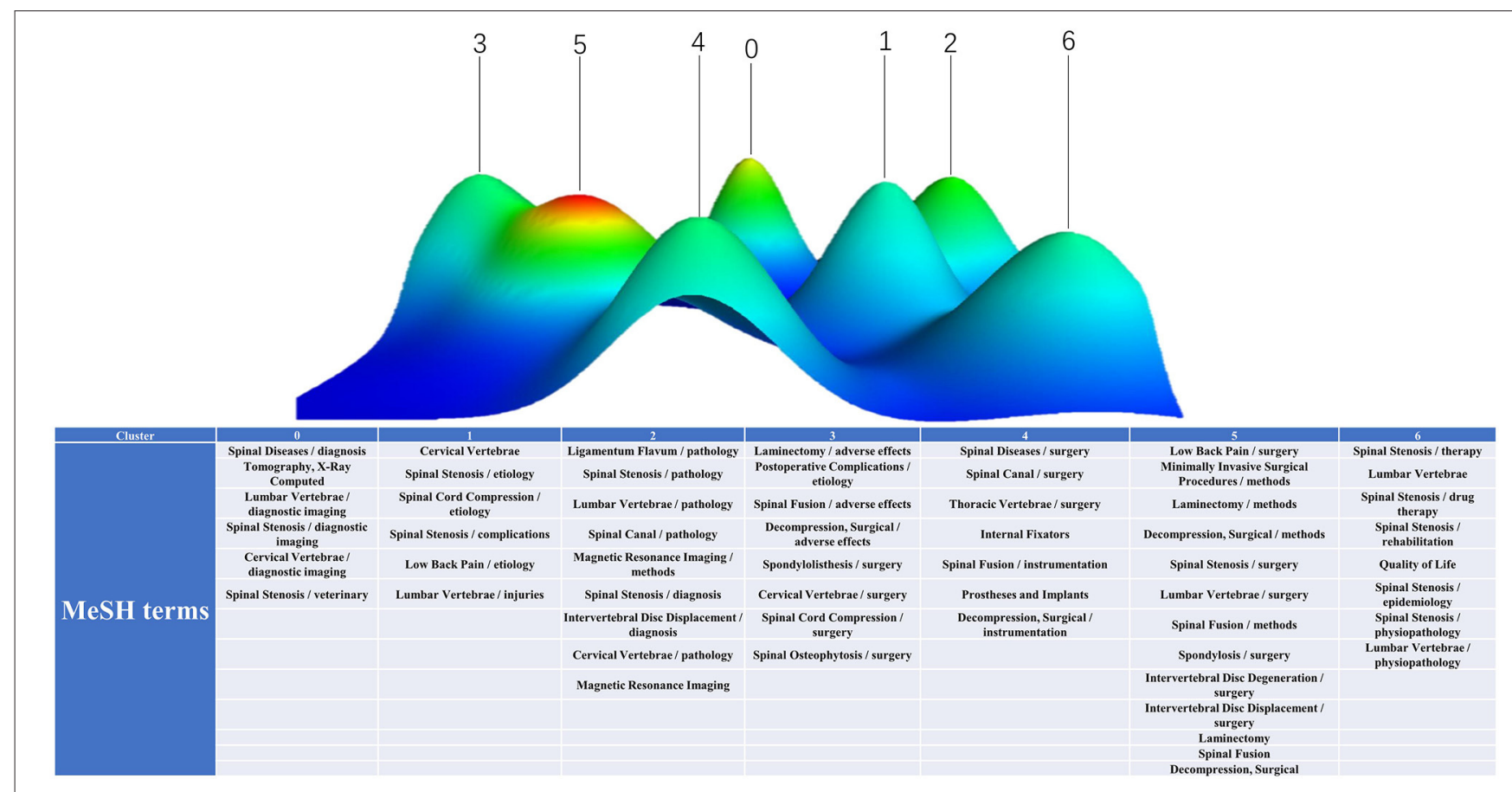

FIGURE 9 | Mountain visualization of biclustering of high-frequency major MeSH terms and articles on spinal stenosis.

idiopathic symptoms. For instance, anterior decompression with spinal fusion occurred before treating cervical stenosis caused by posterior longitudinal ligament ossification (20), and laminectomy could improve radiculopathy effectively using foraminotomy (21). Doctors will formulate the most suitable surgical plan after discussing the patients' pathogenesis and evaluation of the operation. However, unpredictable postoperative symptoms and complications may persist following adequate treatment. Both standard open laminectomy and minimally invasive laminectomy are applied widely to treat cervical spondylosis using lamina trapping and ligament ossification (22). However, postoperative epidural fibrosis with a scar would restrict nerve mobility and increase tension, causing nerve injury and pain (23). Adhesion of the dura mater, canal wall, and ligamentum flavum can also cause cerebrospinal fluid leakage if a tear occurs. Additionally, intraoperative spinal cord injury can lead to paraplegia and incomplete decompression, operative area infection, and spinal atrophy. Regarding incision, anterior surgery exhibits a higher recovery rate and surgical risk, and posterior surgery shows more neurological deterioration. To improve recovery and prevent complications, clinicians strive to optimize the operation and control soft tissue injury and infection. Additionally, the optimization of foraminoscope technology and the improvement in minimally invasive spinal instruments, such as drills and trephines under the microscope, will help improve the success rate of surgery and control the risk of postoperative infection.

Cluster 4 focuses on the role of instrumentations in the rehabilitation of patients with spinal stenosis after decompression. As observed in previous operative cases, pure spinal fusion or laminectomy for decompression results in vertebral instability and increased mobility. Thus, more clinical and fundamental research continues to design multiple internal implantations to stabilize injured vertebral structures. The applied effect of each implantation is adequately inspected. E.H.Kuner evaluated the ASIF internal fixator for the operation of spinal fractures. They observed that internal fixation could effectively reduce the remaining encroachment and remodel the spinal canal, contributing to improving the operative effect and reducing operative complications (24). Since then, various interspinous process decompression (IPD) devices have been tested and applied clinically. These devices would relieve the load on facet joints, restore the height of the intervertebral foramen, and maintain the stability of the spine. However, a follow-up survey also revealed the existing risks, including spinous process fracture, cerebrospinal fluid leakage, and low-back pain (25). At the moment, the indications for these devices require more preoperative examination, intraoperative observation, and postoperative monitoring. Additionally, the prevention methods for post-IPD complications warrant further study.

Cluster 5 focuses on the surgical indications for clinical manifestations. As discussed previously, operative intervention is not inevitable and doctors made optimal plans in which operation would occur for specific conditions. Low back pain, a type of civilized disease prevalent in modern society, occurring mainly in the fourth and fifth lumbar or fifth lumbar and the first sacral vertebrae, is an important indication. Almost eighty percent of adults have pain with osteomyelitis, fracture, and spinal stenosis (26). Operation will be considered after falling flat, with conservative treatment for low back 
pain usually caused by disc herniation, spondylolisthesis, and degenerative disc disease. Minimizing the surgical trauma is also a critical consideration of the surgeon. Thus, in most cases, minimally invasive interventional approaches are the first choice. Orthopedic minimally invasive techniques such as foraminal, interlaminar, and delta mirrors, are widely adopted to improve function and reduce the side effect of drugs (27). Combined with clinical experience, we propose the following three indications for surgery: the patient has unbearable pain and requires surgery when treated conservatively; the patient has sustained intermittent neurogenic claudication and lower extremity symptoms for more than 2-3 months without significant improvement after conservative treatment; or the patient has severe dysfunction, such as progressive weakness of the lower limbs or incontinence. Additionally, surgical intervention using appropriate conservative intervention may maximize the therapeutic effect.

Cluster 6 focuses on the non-operative therapeutic means of spinal stenosis. Conservative treatment is favored because of the lack of collateral damage to the organism. The choice of conservative treatment vs. operation depends on accurate mastery of the clinical examinations including paraspinal tissue morphology, the functional status, and symptoms. Three major strategies are used-oral painkillers, epidural injection, and physical therapy-on the patients in the early stage with moderate symptoms clinically. Among them, epidural corticosteroid injection was confirmed to reduce pain, although the reduction was by a small degree and non-sustained (28). Additionally, epidural injection was more cost-effective and safe. The role of physical therapy in relieving pain and restoring function was limited, but necessary exercise therapy contributed to rehabilitation and complication prevention. Only functional training is less effective than operation in most cases. Non-steroidal anti-inflammatory drugs (NSAIDs) are the most common drug therapy clinically. The pharmacological mechanism involves reducing nerve stimulation, preventing painful secreted substances, and lowering the pain threshold. Thus, NSAIDs cannot fundamentally solve the problem but may reduce pain perception and may lead to drug dependence. Therefore, drug therapy is invalid and must improve. Overall, non-operative therapy is suitable preoperatively for mild to moderate patients and is available in preoperative preparation and postoperative rehabilitation. Additionally, traditional Chinese medicine, massage, and acupuncture show significant improvement effects in mild patients in clinical practice. For patients with different degrees and symptoms, formulating different treatment plans with integrated Chinese and Western medicine may produce the best therapeutic effect, which is also a research hotspot for the future.

As mentioned above, we have described the research status and further trends of spinal stenosis over the last 20 years research. However, reflective research loopholes and limitations may influence the analysis results. First, all the data were obtained from a single database and not involved in most language countries. High-quality literature in other databases was ignored. Collaborative analysis of multiple databases will help to improve the universality of the study. Second, co-word retrieval based on $\mathrm{MeSH}$ terms is limited with occasionality. The number and selection of $\mathrm{MeSH}$ terms will improve the biclustering results. Third, the range of our information retrieval starts from the origination of spinal stenosis studies, which may be a superiority, but could also weaken the recent research trends. Combining more measurement standards will contribute to capturing more research hotspots in the future.

\section{CONCLUSION}

Among each stage of spinal stenosis onset, we conclude the hotspots in pathogenesis and therapeutic research. Pathogenesis has always been the focus of disease research, helping to master and judge progression. The ligmentum flavum and posterior longitudinal ligmentum, which compose the anteroposterior wall of the spinal canal, have attracted increased attention recently. Pathological changes in the ligmentum components, including hypertrophy and ossification, may alter the local morphology, leading to the narrowing of the spinal canal. Furthermore, publishers care more about the selection of therapeutic means in terms of severity. After long-term follow-up surveys and randomized controlled trials, operations combined with proper functional rehabilitation training could maximize the life quality of patients. Additionally, the operative principle is more inclined to minimal invasion and internal implantation, which lowers the risk of infection and postoperative complications. Further refining the pathological classification by optimizing the surgical method and instrument properties will be an important future direction for spinal stenosis.

\section{DATA AVAILABILITY STATEMENT}

The original contributions presented in the study are included in the article/supplementary material, further inquiries can be directed to the corresponding author/s.

\section{AUTHOR CONTRIBUTIONS}

LT: conceptualization, project administration, and writingreview and editing. SZ: data curation and methodology. KY: formal analysis, validation, and writing-original draft. LP: funding acquisition and investigation. KW: resources and software. All authors read and approved the manuscript.

\section{FUNDING}

This work was supported by National key $R \quad \& \quad D$ projects (2017YFC1104903).

\section{ACKNOWLEDGMENTS}

We also thank the Department of Information Management and Information System (Medical) in China Medical University for providing technological support. 


\section{REFERENCES}

1. Miyauchi A, Sumida T, Kaneko M, Manabe H, Adachi N. Morphology and clinical importance of epidural membrane and periradicular fibrous tissue in lumbar spinal stenosis. Eur Spine J. (2017) 26:382-8. doi: $10.1007 / \mathrm{s} 00586-016-4640-\mathrm{z}$

2. Du JP, Fan Y, Hao DJ. Rare hereditary abnormal bone hyperplasia and ossification of the yellow ligament complicated by thoracic spinal stenosis. World Neurosurg. (2018) 115:99-100. doi: 10.1016/j.wneu.2018.04.035

3. Melancia JL, Francisco AF, Antunes JL. Spinal stenosis. Handb Clin Neurol. (2014) 119:541-9. doi: 10.1016/B978-0-7020-4086-3.00035-7

4. Ogink PT, Teunis T, van Wulfften Palthe O, Sepucha K, Bono CM, Schwab $\mathrm{JH}$, et al. Variation in costs among surgeons for lumbar spinal stenosis. Spine J. (2018) 18:1584-91. doi: 10.1016/j.spinee.2018.02.015

5. Forsth P, Olafsson G, Carlsson T, Frost A, Borgstrom F, Fritzell P, et al. A randomized, controlled trial of fusion surgery for lumbar spinal stenosis. New Engl J Med. (2016) 374:1413-23. doi: 10.1056/NEJMoa1513721

6. Ghogawala Z, Dziura J, Butler WE, Dai F, Terrin N, Magge $\mathrm{SN}$, et al. Laminectomy plus fusion versus laminectomy alone for lumbar spondylolisthesis. New Engl J Med. (2016) 374:142434. doi: 10.1056/NEJMoa1508788

7. Yao RQ, Ren C, Wang JN, Wu GS, Zhu XM, Xia ZF, et al. Publication trends of research on sepsis and host immune response during 1999-2019: a 20-year bibliometric analysis. Int J Biol Sci. (2020) 16:27-37. doi: 10.7150/ijbs.37496

8. Ahmad P, Asif JA, Alam MK, Slots J. A bibliometric analysis of Periodontology 2000. Periodontology 2000. (2020) 82:286-97. doi: 10.1111/prd.12328

9. Yang S, Kim CY, Hwang S, Kim E, Kim H, Shim H, et al. COEXPEDIA: exploring biomedical hypotheses via co-expressions associated with medical subject headings (MeSH). Nucleic Acids Res. (2017) 45:D389-96. doi: 10.1093/nar/gkw868

10. Synnestvedt MB, Chen C, Holmes JH. CiteSpace II: visualization and knowledge discovery in bibliographic databases. In: AMIA. Annual Symposium Proceedings. AMIA Symposium. Philadelphia, PA (2005). p. 724-8.

11. Lei C. Development of a Text Mining System Based on the Co-occurrence of Bibliographic Items in Literature Databases. Shenyang: New Technology of Library \& Information Service (2008).

12. Wei WJ, Shi B, Guan X, Ma JY, Wang YC, Liu J. Mapping theme trends and knowledge structures for human neural stem cells: a quantitative and co-word biclustering analysis for the 2013-2018 period. Neural Regener Res. (2019) 14:1823-32. doi: 10.4103/1673-5374.257535

13. Miyazaki M, Takita C, Yoshiiwa T, Itonaga I, Tsumura H. Morphological analysis of the cervical pedicles, lateral masses, and laminae in developmental canal stenosis. Spine. (2010) 35:E1381-5. doi: 10.1097/BRS.0b013e3181e8958f

14. van Eck CF, Spina NT III, Lee JY. A novel MRI classification system for congenital functional lumbar spinal stenosis predicts the risk for tandem cervical spinal stenosis. Eur Spine J. (2017) 26:368-73. doi: 10.1007/s00586-016-4657-3

15. Rowe PC, Marden CL, Heinlein S, Edwards CC II. Improvement of severe myalgic encephalomyelitis/chronic fatigue syndrome symptoms following surgical treatment of cervical spinal stenosis. J Transl Med. (2018) 16:21. doi: 10.1186/s12967-018-1397-7

16. Hohmann D, Kugelgen B, Liebig K. [Chronic spondylogenic cervical myelopathy. Pathogenesis Prognosis, Therapy. (1985) 14:101-11.

17. Kim YU, Park JY, Kim DH, Karm MH, Lee JY, Yoo JI, et al. The role of the ligamentum flavum area as a morphological parameter of lumbar central spinal stenosis. Pain Phys. (2017) 20:E419-24. doi: 10.36076/ppj.2017.E424
18. Wang P, Liu X, Kong C, Liu X, Teng Z, Ma Y, et al. Potential role of the IL17RC gene in the thoracic ossification of the posterior longitudinal ligament. Int $J$ Mol Med. (2019) 43:2005-14. doi: 10.3892/ijmm.2019.4130

19. Prasad SS, O’Malley M, Caplan M, Shackleford IM, Pydisetty RK. MRI measurements of the cervical spine and their correlation to Pavlov's ratio. Spine. (2003) 28:1263-8. doi: 10.1097/01.BRS.0000065570.20 888.AA

20. Masaki Y, Yamazaki M, Okawa A, Aramomi M, Hashimoto M, Koda M, et al. An analysis of factors causing poor surgical outcome in patients with cervical myelopathy due to ossification of the posterior longitudinal ligament: anterior decompression with spinal fusion versus laminoplasty. J Spinal Disord Tech. (2007) 20:7-13. doi: 10.1097/01.bsd.0000211260.28 497.35

21. Snow RB, Weiner H. Cervical laminectomy and foraminotomy as surgical treatment of cervical spondylosis: a follow-up study with analysis of failures. J Spinal Disord. (1993) 6:245-50; discussion 250-1. doi: 10.1097/00002517-199306030-00011

22. Alimi M, Hofstetter CP, Pyo SY, Paulo D, Hartl R. Minimally invasive laminectomy for lumbar spinal stenosis in patients with and without preoperative spondylolisthesis: clinical outcome and reoperation rates. $J$ Neurosurg Spine. (2015) 22:339-52. doi: 10.3171/2014.11.SPINE 13597

23. Lin CL, Jou IM, Wu CY, Kuo YR, Yang SC, Lee JS, et al. Topically applied cross-linked hyaluronan attenuates the formation of spinal epidural fibrosis in a swine model of laminectomy. Sci Rep. (2019) 9:14613. doi: 10.1038/s41598-019-50882-x

24. Kuner EH, Schlickewei W, Kuner A, Hauser U. Restoration of the spinal canal by the internal fixator and remodeling. Eur Spine J. (1997) 6:41722. doi: $10.1007 / \mathrm{BF} 01834072$

25. Gazzeri R, Galarza M, Neroni M, Fiore C, Faiola A, Puzzilli F, et al. Failure rates and complications of interspinous process decompression devices: a European multicenter study. Neurosurg Focus. (2015) 39:E14. doi: 10.3171/2015.7.FOCUS15244

26. van den Berg R, Jongbloed EM, de Schepper EIT, Bierma-Zeinstra SMA, Koes BW, Luijsterburg PAJ. The association between pro-inflammatory biomarkers and nonspecific low back pain: a systematic review. Spine J. (2018) 18:214051. doi: 10.1016/j.spinee.2018.06.349

27. Urits I, Burshtein A, Sharma M, Testa L, Gold PA, Orhurhu V, et al. Low back pain, a comprehensive review: pathophysiology, diagnosis, and treatment. Curr Pain Headache Rep. (2019) 23:23. doi: 10.1007/s11916-01 9-0757-1

28. Chou R, Hashimoto R, Friedly J, Fu R, Bougatsos C, Dana T, et al. Epidural corticosteroid injections for radiculopathy and spinal stenosis: a systematic review and meta-analysis. Ann Int Med. (2015) 163:37381. doi: 10.7326/M15-0934

Conflict of Interest: The authors declare that the research was conducted in the absence of any commercial or financial relationships that could be construed as a potential conflict of interest.

Copyright (๑) 2021 Yang, Pei, Wen, Zhou and Tao. This is an open-access article distributed under the terms of the Creative Commons Attribution License (CC BY). The use, distribution or reproduction in other forums is permitted, provided the original author(s) and the copyright owner(s) are credited and that the original publication in this journal is cited, in accordance with accepted academic practice. No use, distribution or reproduction is permitted which does not comply with these terms. 